\title{
THERMAL STABILITY OF LASER TREATED DIE MATERIAL FOR SEMI- SOLID METAL FORMING
}

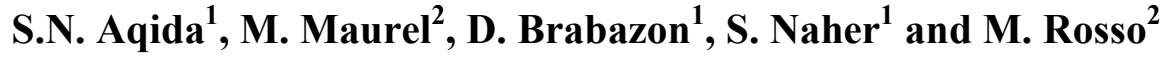 \\ ${ }^{1}$ Materials Processing Research Centre, Dublin City University, Ireland \\ ${ }^{2}$ Faculty of Engineering, Politecnico Di Torino, Italy
}

\begin{abstract}
This paper presents laser surface modification work performed to improve the lifetime of die materials. Die material AISI H13, with typical hardness in the range of 42 to 48 HRC, offers high wear and corrosion resistance. However the cyclic high temperature conditions along with exposure to high viscosity molten metal in semi-solid forming cause the die to wear and crack with resultant shortened die lifetime. In this study, the thermal stability of die material at elevated temperature was investigated through micro-hardness testing and a metallographic study. AISI H13 samples were laser glazed using $\mathrm{CO}_{2}$ continuous wave mode laser with $10.6 \mu \mathrm{m}$ wavelength. Samples were attached to a specially designed rotating chuck to enable it to be rotated at speeds up to $1500 \mathrm{rpm}$ and allow flat surface glazing to take place. The microhardness was measured for as-glazed samples and annealed samples which were held at temperatures ranging from $550^{\circ} \mathrm{C}$ to $800^{\circ} \mathrm{C}$ with $50^{\circ} \mathrm{C}$ intervals. The metallographic study conducted examined the formation of three zones at different depths which were the glazed zone, the heat affected zone and the substrate. As a result of rapid heating and cooling from the laser glazing process, a metallic glass layer was developed which exhibited an average micro-hardness of $900 \mathrm{HV}$ when exposed to $3.34 \mathrm{E}+10 \mathrm{~W} / \mathrm{m}^{2}$ laser irradiance within a range of 3.64 to $5.66 \mathrm{~ms}$ exposure time. Crystallization in glazed zone increased as the annealing temperature increased. As the annealing temperature reached above approximately $600^{\circ} \mathrm{C}$, the microhardness decreased to approximately $600 \mathrm{HV}$ (equivalent to approx. $54 \mathrm{HRC}$ ) due to local crystallization. These findings show potential direct application of glazed dies for non-ferrous semi-solid forming and the requirement for thermal barrier protection for application at higher temperatures.
\end{abstract}

KEYWORDS: Laser glazing, thermal stability, micro-hardness, annealing and die material.

\section{INTRODUCTION}

Laser glazing has been studied as a way of surface hardening on die, in order to overcome the premature failure of die application in semi solid casting by developing an amorphous layer on the surface. Though there is current approach such as coating implemented in sustaining the die application, the difficulties are to meet the six requirements of effective coating; excellent bonding, adequate thickness, absence of flaws, suitable mechanical properties, thermal shock resistance and high temperature stability [1].

In semi-solid processing, the forming temperatures are considerably lower than in liquid metal die-casting which can extend die life. Die material AISI H13, with typical hardness in the range of 40 to 50 HRC [2], offers high wear and corrosion resistance. The cyclic high temperature conditions along with exposure to high viscosity molten metal in semi-solid forming would cause the die to wear and crack with resultant shortened die lifetime. Though H13 steels be able to withstand the relatively high working temperatures involved, however when the temperature is above $600^{\circ} \mathrm{C}$, the dies are easy to wear and collapse, so the die life at high temperature is not long enough [3].

In previous work [1], laser glazed steel surface exhibited enhanced hardness property as much as $30 \%$ compared to the substrate as a result of fine grains and secondary carbides formation. Reviewing other study on laser glazing [4], a thin layer of laser glazed surface possessed hard nonequilibrium microstructures that were intimately bonded to the substrate, and the modified region itself. A number of phases were present during the process due to rapid solidification and rapid cooling. However, referring to Yang et al [6], an amorphous layer was developed through laser glazing process even at multi pass region where overlapped zones did not recrystallize during the consequent laser pass. To improve the die lifetime, surface modification using laser glazing was investigated in this work. The thermal stability of die material at elevated temperature was investigated through microhardness testing and metallographic study. The combination of wear resistance, high strength and thermal stability can increase significantly the lifetime of the die and therefore decrease unit production cost. 


\section{EXPERIMENTAL}

AISI H13 samples prepared in this study were laser glazed in as received condition. The chemical composition of AISI H13 detected from the energy-dispersive X-ray spectroscopy is in Table 1.

A specially designed rotating chuck is attached to a moving bed beneath the laser head which produce both rotational and linear movement of the sample as shown in Figure 1. Samples were glazed by continuous operating mode of $\mathrm{CO}_{2}$ laser. The laser system specifications are detailed in Table 2.

To ensure the exposure time and power density affecting the surface as referred to previous works [4-8], the rotation speed was kept constant at $1500 \mathrm{rpm}$ which allowed the exposure time to increase as the surface radius decreased.
The laser started at the edge of the sample with maximum radius of $20 \mathrm{~mm}$ and stopped prior the centre point to avoid accumulation of high concentration laser energy.

Samples were sectioned and metallographic preparation was done through grinding, polishing and nital (2-10\%) etching. Formation of glazed layer was examined under Scanning Electron Microscope (SEM) which also achievable for depth and grain size measurement. The difference of microhardness property in laser glazed surface and annealed samples was measured using Vickers test at $981 \mathrm{mN}$ load. Annealing process was conducted at various temperatures of $550^{\circ} \mathrm{C}, 600^{\circ} \mathrm{C}, 650^{\circ} \mathrm{C}, 700^{\circ} \mathrm{C}$, $750^{\circ} \mathrm{C}$ and $800^{\circ} \mathrm{C}$. Samples were annealed for 15 minutes and cooled in ambient air to observe the effects of elevated temperatures on the laser glazed surface properties including the structure and hardness.

Table 1: Chemical composition of AISI H13

\begin{tabular}{|c|c|c|c|c|c|c|c|c|c|c|c|}
\hline Element & $\mathrm{C}$ & $\mathrm{Mn}$ & $\mathrm{Si}$ & $\mathrm{Cr}$ & $\mathrm{Ni}$ & $\mathrm{Mo}$ & $\mathrm{V}$ & $\mathrm{Cu}$ & $\mathrm{P}$ & $\mathrm{S}$ & $\mathrm{Fe}$ \\
\hline $\mathrm{wt} \%$ & $0.32-0.45$ & $0.20-0.50$ & $0.80-1.20$ & $4.75-5.50$ & 0.30 & $1.10-1.75$ & $0.80-1.20$ & 0.25 & 0.03 & 0.03 & balance \\
\hline
\end{tabular}

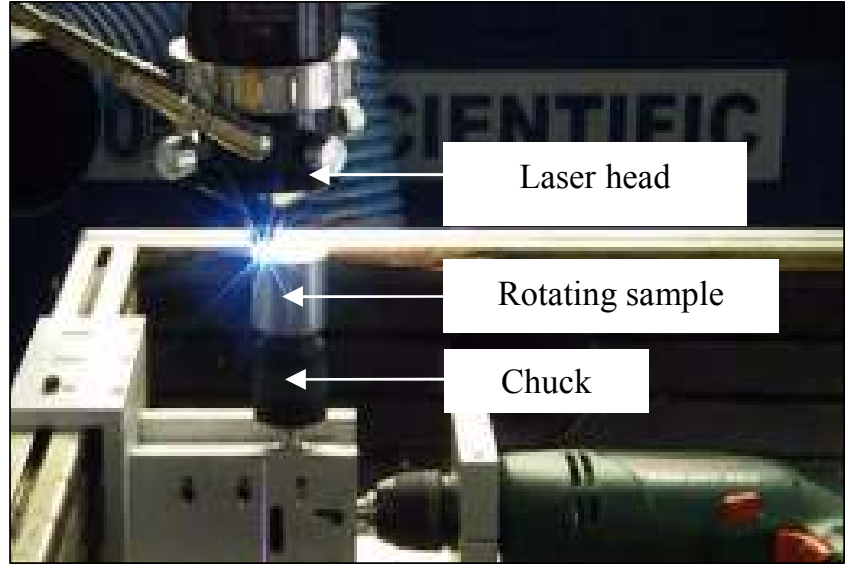

Figure 1: Laser glazing apparatus

Table 2: Laser system specifications

\begin{tabular}{lc}
\hline Power & $1.2 \mathrm{~kW}$ \\
\hline Beam geometry & Circle \\
Focal position & Surface \\
Spot size & $0.2 \mathrm{~mm}$ \\
Assist gas & Argon \\
Laser beam mode & $\mathrm{TEM}_{00}$ \\
Laser wavelength & $10.6 \mu \mathrm{m}$ \\
\hline
\end{tabular}

\section{RESULTS AND DISCUSSION}

\subsection{EFFECT OF EXPOSURE TIME ON GRAIN SIZE}

Development of grain size in laser glazing process is depends on the cooling rate. Without a particular thermal modeling or thermal imaging camera to determine the temperature gradient, the cooling rate is estimated by calculating the exposure time. Due to radial change of the sample through the process, a range of exposure time was gained which result in variations of grain size.

Figure 2 shows an SEM back scattered detector micrograph of as received $\mathrm{H} 13$ tool steel with a magnification of $7.92 \mathrm{kX}$. From the micrograph, it is found that the as received $\mathrm{H} 13$ tool steel has grain size approximately $3-9 \mu \mathrm{m}$.

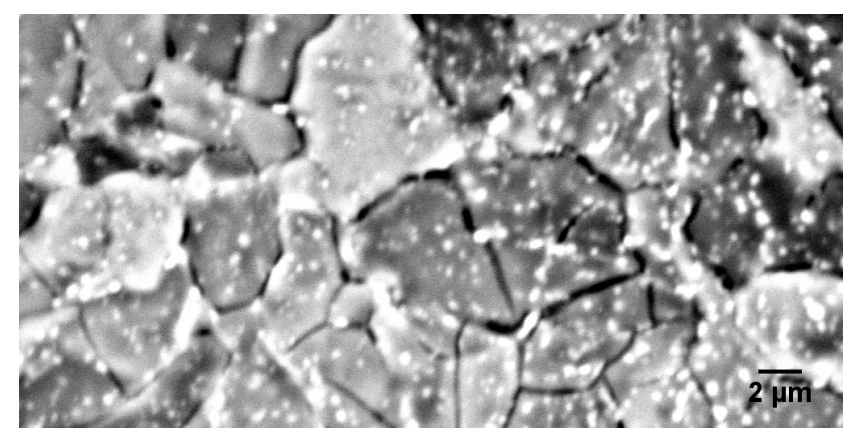

Figure 2: SEM back-scattered detector micrographs of asreceived H13 (7.92 kX magnification) 


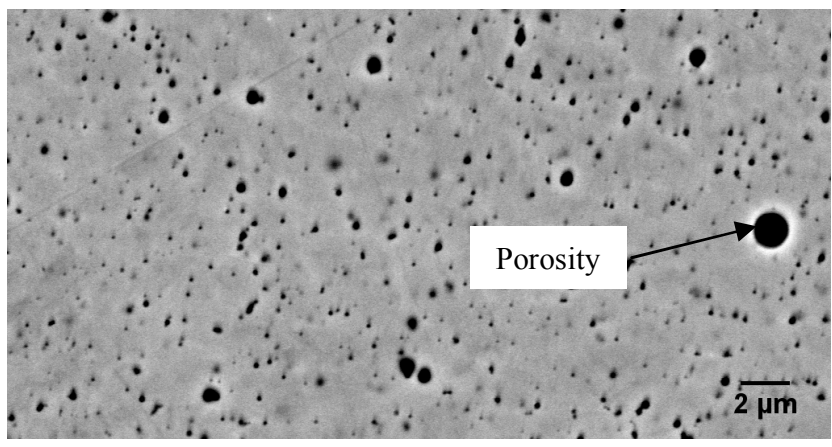

(a)

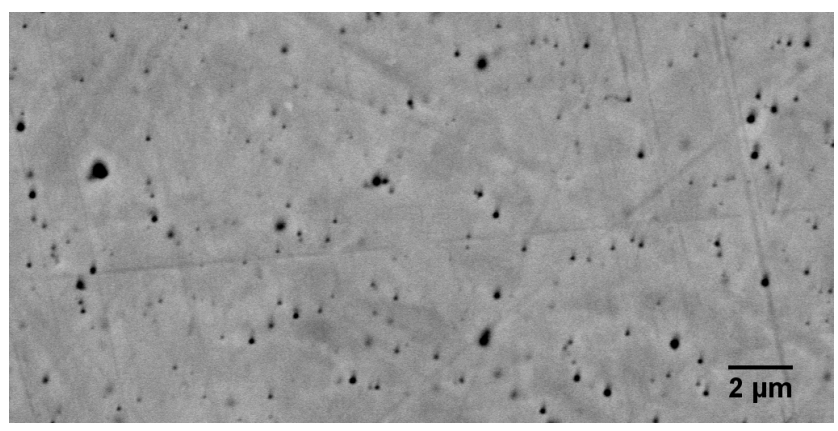

(b)

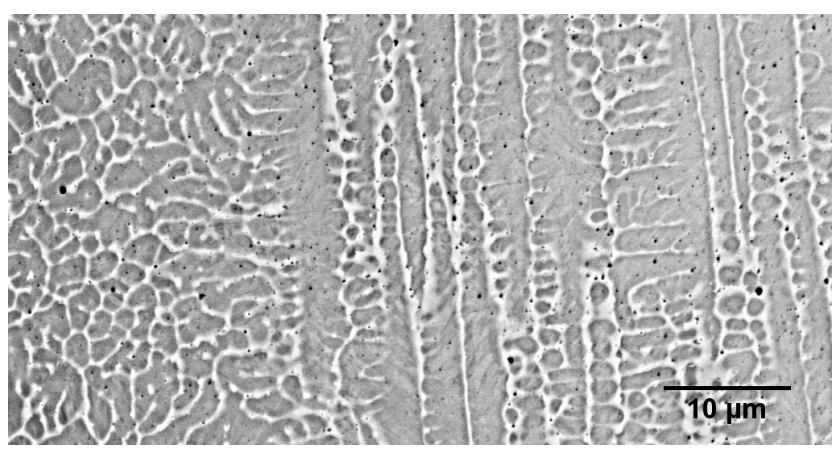

(c)

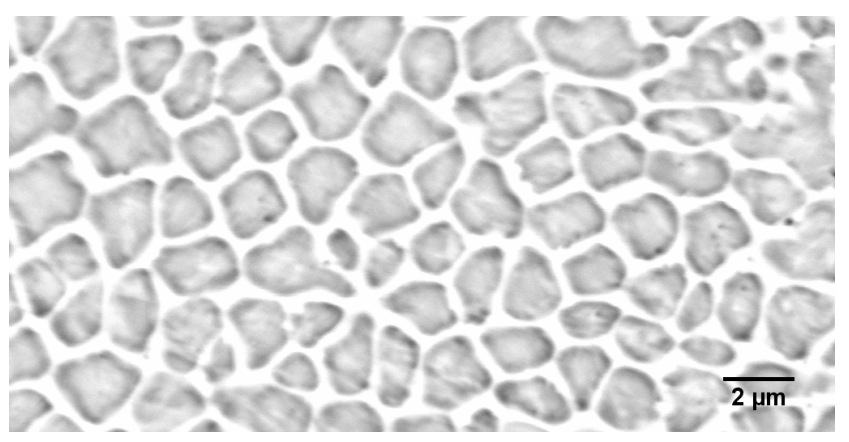

(d)

Figure 3: SEM back-scattered detector micrographs of grain size in laser glazed tool steel at exposure time of (a) $4.63 \mathrm{~ms}$ (9.14 kX magnification), (b) $3.64 \mathrm{~ms}$ (11.73 kX magnification) (c)1.82 ms (4.70 kX magnification)and (d)less than $1.82 \mathrm{~ms}$ (12.88 kX magnification).
Micrographs in Figure 3 show the increasing grain size towards the edge of the sample as a result of decreasing exposure time. The amorphous structure in Figure 3(a) and (b) is resulted from exposure time between $3.64 \mathrm{~ms}$ to 5.66 $\mathrm{ms}$, whereas nano gain size was observed in micrographs in Figure 3(c) and (d) with exposure time ranging from $2.31 \mathrm{~ms}$ to $2.68 \mathrm{~ms}$. Longer exposure however developed plenty of large porosity, and tribological defects as pointed out in Figure 3(a). In Figure 3(c) and (d), less exposure time would cause insufficient energy to melt the entire surface which exhibits nano to micron grain size (200$2000 \mathrm{~nm})$. Porosity was also avoidable in Figure 3(d) as less laser energy irradiated on the surface. Figure 2(e) depicts the as-received H13 grain size (3-9) for comparison mean.

\subsection{MICROHARDNESS OF LASER GLAZED H13}

As a result of rapid heating and cooling, a treated layer was developed on the tool steel surface which exhibited an average micro-hardness of $900 \mathrm{HV}$ (equivalent to approximately $67 \mathrm{HRC}$ ). It can be seen in Figure 4, an increase in hardness from $800 \mathrm{HV}$ to $1200 \mathrm{HV}$ were achieved in the treated surface. At room temperature, 1200 $\mathrm{HV}$ is the maximum hardness that was achieved within the treated region. Then the hardness value start decreasing from $1200 \mathrm{HV}$ to $300 \mathrm{HV}$ when reaching deeper into the substrate. $300 \mathrm{HV}$ is the hardness for the as received $\mathrm{H} 13$ tool steel. Understanding the micromechanisms of the crystallization to impede or control crystallization is therefore prerequisite for most applications, as the stability against crystallization determines their effective working limits [8].

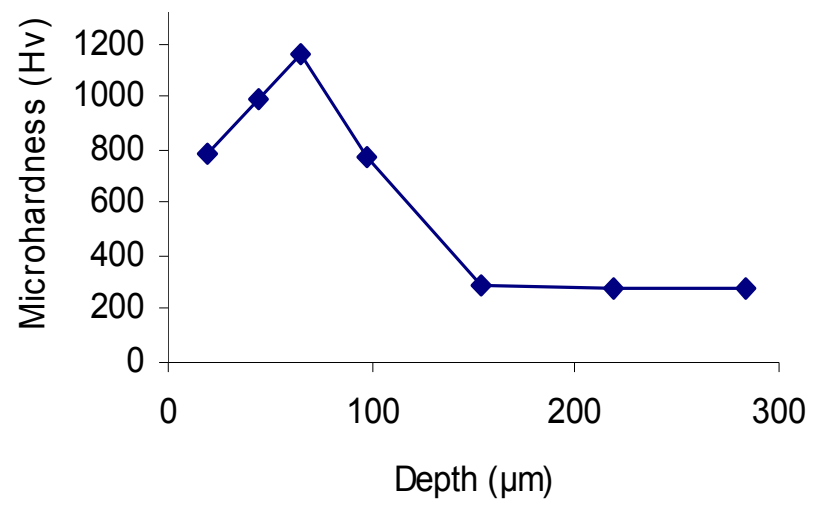

Figure 4: Microhardness of glazed layer at room temperature

\subsection{THERMAL INSTABILITY OF LASER GLAZED SURFACE}

A striking increase of the surface hardness is significant to endure wear and elevated temperature applications. In spite of that, the amorphous material formation is instable when sufficient temperature is applied. This is due to 
crystallization of the amorphous layer at various annealing temperature which presented by changes in microhardness property.

Figure 3 indicates as the annealing temperature reached above approximately $600^{\circ} \mathrm{C}$, the micro-hardness decreased to approximately $600 \mathrm{HV}$ (equivalent to approx. $54 \mathrm{HRC}$ ) due to local crystallization. Basically, the crystallization in glazed zone increased as the annealing temperature increased.

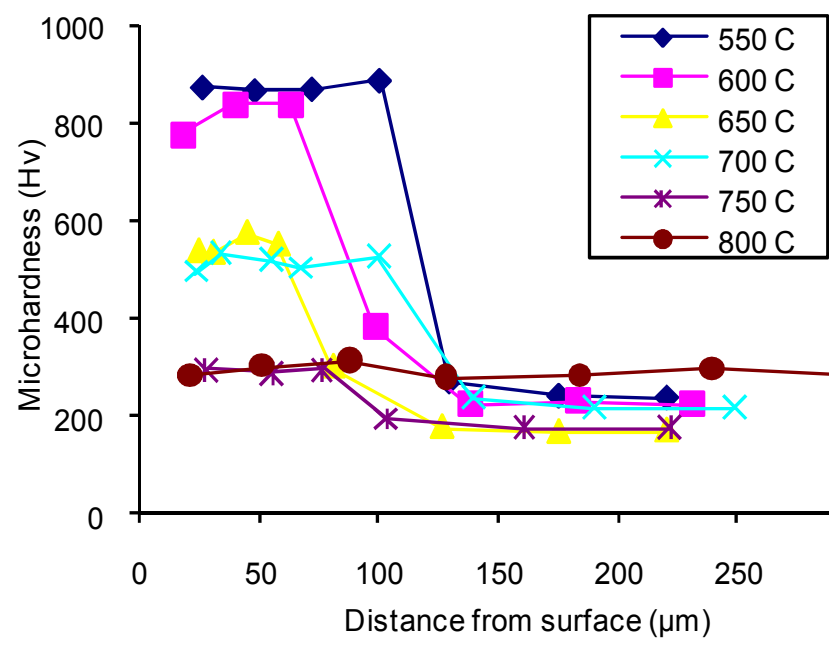

Figure 5: Microhardness as a function of the distance from surface at different annealing temperature.

Parallel with previous works of Nieh and Wadsworth [10], the changes of mechanical properties in amorphous metal are characterized by inhomogenous and homogenous deformation at low and high temperature respectively. Due to stability of crystal structure, a consistent deformation occurred as shown by Figure 5 where at $800^{\circ} \mathrm{C}$ annealing temperature, the microhardness of the laser glazed layer is consistently at $\sim 280 \mathrm{HV}$ along the depth. This indicates a fully crystalline structure was transformed at $800^{\circ} \mathrm{C}$ as well as increasing grain structure. Temperatures less than $800^{\circ} \mathrm{C}$ affecting the surface to exhibit inconsistent microhardness especially at approximately less than $100 \mu \mathrm{m}$ depth probably due to metastable structure of laser glazed surface.

\section{CONCLUSION}

This study is beneficial in pointing out the effective working limit for laser glazed die surface through observation and measurement of surface structure and hardness. These findings also show potential direct application of glazed dies for non-ferrous semi-solid forming and the requirement for thermal barrier protection for application at higher temperatures.

\section{ACKNOWLEDGEMENT}

The authors would like to acknowledge the technical support from Martin Johnson and Michael May of School of Mechanical and Manufacturing Engineering at Dublin City University in performing this study. The authors would also like to acknowledge the support from the Ministry of Higher Education, Malaysia for funding the entire duration of study.

\section{REFERENCES}

[1] W. Jiang and P. Molian. Nanocrystalline TiC powder alloying and glazing of $\mathrm{H} 13$ steel using a $\mathrm{CO}_{2}$ laser for improved life of die-casting dies. Surface and Coatings Technology, 135:139-149, 2001.

[2] H. Yan, J. Hua, and R. Shivpuri, Flow stress of AISI H13 die steel in hard machining. Materials \& Design, 28:272-277, 2007.

[3] W. Li and N. Qu, Study of high temperature wear resistance of hot work steel for magnesium alloy die casting. Advanced Materials Research, 26-28:33-36, 2007.

[4] R.J. DiMelfi, P.G. Sanders, B. Hunter, J.A. Eastman, K.J. Sawley, K.H. Leong, and J.M. Kramer, Mitigation of subsurface crack propagation in railroad rails by laser surface modification. Surface and Coatings Technology, 106:30-43, 1998.

[5] Y. Yang, Y. Song, W. Wu and M. Wang. Multi-pass overlapping laser glazing of $\mathrm{FeCrPC}$ and $\mathrm{CoNiSiB}$ alloys. Thin Solid Films, 323:199-202, 1998.

[6] D. Brabazon, S. Naher and P. Biggs, Laser surface modification of tool steel for semi-solid steel forming, Solid State Phenomena, 141-143:255-260, 2008.

[7] D. Brabazon, S. Naher, and P. Biggs.Glazing of tool dies for semi-solid steel forming. Int. J. Mater. Form. DOI 10.1007/s12289-008-0, Springer/ESAFORM 2008.

[8] D.W. Hetzner, Laser glazed bearings. In 5th International Symposium on Bearing Steels, pages 471-498, 1998.

[9] Glassy Metals I: Ionic structure, electronic transport and crystallisation. In H-J. Guntherodt and H. Beck, editors, Topics in Applied Physics, Springer Berlin, Germany, 1981.

[10] T.G. Nieh and J. Wadsworth, Homogeneous deformation of bulk metallic glasses, Scripta Materialia, 54:387-392, 2005. 